\title{
Aegean Journal of Obstetrics and Gynecology
}

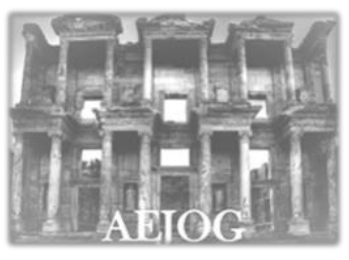

Original Article

\section{Cerclage outcomes in singleton pregnancies at risk for preterm birth following assisted reproductive treatments}

\author{
Gulnaz Sahin a, +, (iD), Ferruh Aceta, (iD), Ege Nazan Tavmergen Goker a, (iD, Erol \\ Tavmergen a, (iD
}

a Family Planning and Infertility Research and Practice Center, Ege University, İzmir, Turkey

A B S T R A C T

Objective: We aimed to evaluate the obstetric and neonatal outcomes of singleton pregnancies at risk for preterm birth (PTB) following assisted reproductive treatments and underwent cervical cerclage placement.

Material and methods: A total of 42 women with singleton pregnancies following ART who underwent cerclage between 2009-2021 were included in this retrospective study. Indications of the cerclage procedure, gestational age at cerclage placement and delivery, neonatal birthweight, and requirement for admission to the neonatal unit of newborns were evaluated.

Results: Of that cerclage placement performed in women with a history of second-trimester loss or preterm birth (19\%), women with suspected cervical insufficiency according to pre-pregnancy evaluation $(52.4 \%)$, women with the unicornuate uterus $(4.8 \%)$, women with short cervix and/or dilated internal os on ultrasonography $(11.9 \%)$, and women with detection of cervical dilatation/shortening beyond 20 weeks of gestation (11.9\%). Of the total group, $7.1 \%$ resulted in late miscarriages, while remaining $92.9 \%$ ended with a live birth with median gestational age at delivery of 37.7 weeks (interquartile range $=1.57)$. Of those live births, $92.3 \%(36 / 39)$ delivered at $>34$ weeks and \%74.4 (29/39) delivered at term. Except one neonatal death due to extremely PTB at 26th weeks, all infants were discharged from the hospital with well condition.

Conclusion: ART pregnancies are evaluated as a special group as having a higher PTB risk at baseline. Cerclage may be considered in broader indications for suspected cervical insufficiency in these pregnancies. There is need for further studies on the effectiveness of cerclage in these ART pregnancies with suspected cervical insufficiency based on different criteria used.

Keywords: cerclage; assisted reproductive technology; singleton pregnancy; preterm birth; cervical insufficiency

A R T I CLE IN F O

Doi: $10.46328 /$ aejog.v3i3.108

Article history:

Received: 27 September 2021

Revision received: 17 October 2021

Accepted: 14 Novenber 2021

\section{Introduction}

Preterm birth (PTB) is defined as the delivery before the 37th gestational weeks [1] and it is the most common cause of neonatal morbidity and mortality worldwide [2]. Moreover, PTB associates with long term neurodevelopmental problems and increased risk of chronic diseases for survivors. Apart from the induction of labor before term due to distinct fetal and maternal complications (iatrogenic PTB), majority of the preterm births are spontaneous [3]. Despite many obstetric, medical, socio-demographic and nutritional risk factors have been associated with spontaneous PTB's, the underlying reason of PTB cannot be understood in majority of the cases [4].The prediction of PTB and preventive measures are utmost important for obstetric care worldwide, due to its high incidence and association with infant morbidity and mortality. The increased risk of PTB in both singleton and twin IVF pregnancies compared to natural conceptions has been reported in previous studies and meta-analyses [5-9]. It has been indicated that infertility itself might be a risk factor, possibly related with etiologies of infertility such as presence of congenital uterine anomalies and advanced maternal age.
In addition, the assisted reproductive technology (ART) procedures were reported to be a possible contributing factor for the increased risk of PTB's in singletons [8].

Considering the increasing number of pregnancies after the ART treatments and economical and emotional burden of such treatments, follow-up of these pregnancies also needs further attention.

Cervical cerclage is one of the preventive approaches in women at risk for PTB particularly for those with suspected cervical insufficiency. The procedure can be performed either by the transvaginal or transabdominal route, and the most commonly used methods for cerclage are the McDonald and Shirodkar techniques [10]. However, diagnosis of cervical insufficiency and therefore the indications for placement of cervical cerclage are still one of the challenging issues in obstetrics due to the lack of evident diagnostic criteria. Currently, a number of wide practice variations exists for the indications of the cerclage procedure [11], and there are differences in the relevant guidelines on the use of cerclage due to the heterogeneity of the literature on the subject [10]. 
The history of unexplained second trimester pregnancy loss/losses, painless cervical dilatation at physical examination during second trimester or previous PTB with detection of cervical shortening $(<25 \mathrm{~mm})$ before the 24th weeks of gestation in singleton pregnancies are recommended indications for placement of the cervical cerclage by professional societies [11-13].

The American College of Obstetricians and Gynecologists (ACOG) guideline [12] recommends cerclage for the women with one or more previous second-trimester loss while the Society of Obstetricians and Gynecologists of Canada (SOGC) [11] and Royal College of Obstetricians and Gynecologists (RCOG) [13] advise history-indicated cerclage for the women with a history of 3 or more late-miscarriages or preterm births. Additionally, cerclage placement can be performed in selected patients in emergency setting such with a dilated cervix without active labor, not having vaginal bleeding, abruptio placentae or intraamniotic infection [11-13]. In a previous meta-analysis from Berghella et al (2011), it was shown that the procedure can decrease the risk of PTB and neonatal death in women with previous spontaneous PTB with a short cervical length [14]. In a recent Cochrane review, including 15 randomized studies on the effectiveness of cervical cerclage in singleton pregnancies with high risk for PTB, the procedure has been associated with reduced risk of PTB compared to expectant management [15].

The role of cerclage in twin pregnancies is still under debate. Cerclage placement in twin pregnancies with shortened cervical length has not been recommended, moreover, the procedure has been associated with increased incidence of PTB, based on a previous meta-analysis from Berghella et al (2005) [16]. In a Cochrane meta-analysis (2014) including 122 women with twin pregnancies highlighted that, there was no evidence for effectiveness of cerclage in preventing PTB in twin gestations [17] although, it has been stated that the included low number of trials with heterogeneity.

Effectiveness of the cerclage procedure for other risk factors for cervical insufficiency such in women with congenital Mullerian anomalies or previous surgical trauma of cervix (e.g. cervical electrosurgical excision, cone biopsy, mechanical dilatation of cervix or lacerations) are also still under debate. The aim of this study was to evaluate the obstetric and neonatal outcomes of singleton pregnancies at risk for PTB following ART and underwent cervical cerclage placement to reduce the risk of PTB in our clinic.

\section{Material and methods}

All cervical cerclage procedures performed between 2009 and 2021 at our institution for women at risk for PTB during their ART pregnancies were retrospectively evaluated. The singleton pregnancies obtained following ART treatment and at risk for PTB due to i) previous obstetric history (presence of one or more second trimester pregnancy loss/or preterm birth) ii) suspected cervical insufficiency; cervical dilatation without resistance to cervical dilatators ( $>6$ Hegar dilators) during previous hysteroscopic intervention iii) presence of uterine anomalies iv) detection of short cervix and/or dilated internal cervical os on TVUSG scan before 20 weeks of gestation or $v$ ) detection of cervical dilatation/shortening beyond 20th weeks of gestation (late cerclage) were the inclusion criteria. Multiple pregnancies were excluded from the study.

Transvaginal cervical cerclage procedure using the McDonald's technique under intravenous general anesthesia was performed by a senior obstetrician for all included patients. A nonabsorbable Mersilene tape (Ethicon) suture was utilized for the procedure. Transvaginal progesterone supplementation was used until the 10th-12th week of gestation for these ART pregnancies routinely. In our clinical protocol, prophylactic depot progesterone (intramuscular, weekly) until the 24th week of gestation and monthly, intramuscular depot penicillin until the delivery was used routinely following the cerclage placement.

Maternal age, type of the ART treatment (whether the intracytoplasmic sperm injection/fresh embryo transfer or frozen/thawed embryo transfer), duration of infertility, indication of cerclage procedure and gestational age at cerclage placement was recorded. Gestational age at delivery, neonatal birthweight and requirement for the admission of newborns to neonatal unit were evaluated outcomes. These outcomes were obtained from the hospital records and from the self-reports of patients whom delivered outside our hospital.

Categorical variables are expressed as frequencies and percentages (\%).

Descriptive statistics for continuous variables were presented as mean, standard deviation (SD) or median, interquartile range (IQR) according to the normality of the data distribution. The SPSS software (ver. 25.0, SPSS Inc., USA) was used for the analyses.

\section{Results}

A total of 42 women who underwent cerclage procedure during the study period met the inclusion criteria. All women had singleton pregnancies following ART procedures with at risk for PTB. Regarding the mode of conception, 35/42 (83.3\%) women conceived following ICSI/fresh embryo transfer and $7 / 42(16.7 \%)$ conceived following frozenthawed embryo transfer cycle. Of those 23 (54.7\%) were primary and $19(45.3 \%)$ were secondary infertile patients with a median infertility duration of 5 (IQR $=7.2$, min$\max =1-21$ ) years and the median number of previous embryo transfer cycle attempts of $2.1(\mathrm{IQR}=2$, min-max $=1$ $5)$ before their pregnancies were obtained. The ART indications were; male infertility $(n=11,26.2 \%)$, ovulatory $(n=4,9.6 \%)$, idiopathic $(n=24,57.1 \%)$ or tubal factor infertility $(n=3,7.1 \%)$. The characteristics of the of the study group are shown in Table 1.

Table 1. Characteristics of the group

\begin{tabular}{|l|l|}
\hline Maternal age & $\mathbf{3 2 . 5 \pm 4 . 0}$ \\
\hline$<30$ & $10(23.8)$ \\
\hline $30-35$ & $20(47.6)$ \\
\hline$>35$ & $12(28.6)$ \\
\hline History of $1^{\text {st }}$ trimester loss & $12(28.6)$ \\
\hline History of $2^{\text {nd }}$ trimester loss & $7(16.7)$ \\
\hline Previous PTB & $1(2.4)$ \\
\hline Previous stillbirth & $1(2.4)$ \\
\hline Gravidity & \\
\hline 1 & $23(54.8)$ \\
\hline 2 & $9(21.4)$ \\
\hline $3-4$ & $10(23.8)$ \\
\hline Parity & \\
\hline 0 & $38(90.5)$ \\
\hline 1 & $4(9.5)$ \\
\hline $\begin{array}{l}\text { ART method used for the current } \\
\text { pregnancy }\end{array}$ & \\
\hline ICSI/ fresh embryo transfer & $35(83.3)$ \\
\hline Frozen embryo transfer & $7(16.7)$ \\
\hline
\end{tabular}

Data are presented as $n(\%)$, mean \pm standard deviation

Of those cerclage placement was performed in women with a history of second trimester loss or PTB $(n=8 / 42,19 \%)$, women with suspected cervical insufficiency (according to ease of the cervical dilatation without resistance to $>6$ Hegar dilators during previous hysteroscopic evaluation) $(n=22 / 42,52.4 \%)$, women with a unicornuate uterus $(n=2 / 42,4.8 \%)$, women with short cervix and/or dilated internal os on TV scan during their pregnancies $(n=5 / 42$, $11.9 \%)$, and another 5/42 (11.9\%) women with detection of cervical dilatation/shortening beyond 20 weeks of gestation (late cerclage group) (range 21-27 weeks). Cerclage indications of the study group with pregnancy outcomes are shown in Table 2. 
Table 2. Cerclage indications and pregnancy outcomes

\begin{tabular}{|c|c|c|c|c|c|c|c|}
\hline & n (\%) & $\begin{array}{l}\text { GA at } \\
\text { cerclage* } \\
\text { (weeks) }\end{array}$ & $\begin{array}{l}\text { Late } \\
\text { pregnancy } \\
\text { loss } \\
\mathrm{n}(\%)\end{array}$ & $\begin{array}{l}\text { PTB } \\
<28 \text { weeks } \\
\mathrm{n}(\%)\end{array}$ & $\begin{array}{l}\text { PTB } \\
32-34 \text { weeks } \\
\text { n }(\%)\end{array}$ & $\begin{array}{l}\text { PTB } \\
34-37 \text { weeks } \\
\text { n (\%) }\end{array}$ & $\begin{array}{l}\text { Term Delivery } \\
>37 \text { weeks } \\
\mathrm{n}(\%)\end{array}$ \\
\hline $\begin{array}{l}\text { History of second } \\
\text { trimester loss or PTB }\end{array}$ & $8(19)$ & $14.3(1.7)$ & $1(12.5)$ & $1(12.5)$ & - & $1(12.5)$ & $5(62.5)$ \\
\hline $\begin{array}{l}\text { Suspected CI } \\
\text { according to previous } \\
\mathrm{H} / \mathrm{S} \text { evaluation }\end{array}$ & $22(52.4)$ & $14.4(1.6)$ & $2(9.1)$ & - & $1(4.5)$ & $4(18.2)$ & $15(68.2)$ \\
\hline Unicornuate uterus & $2(4.8)$ & 16.3 & - & - & - & - & $2(100)$ \\
\hline $\begin{array}{l}\text { Short cervix and/or } \\
\text { dilated internal os on } \\
\text { TV scan during }<20 \\
\text { weeks of gestation }\end{array}$ & $5(11.9)$ & $14.4(2.8)$ & - & - & - & $1(20)$ & $4(80)$ \\
\hline $\begin{array}{l}\text { Detection of cervical } \\
\text { dilatation/ } \\
\text { shortening beyond } 20^{\text {th }} \\
\text { weeks (late cerclage) }\end{array}$ & $5(11.9)$ & $25.7(4.9)$ & & - & $1(20)$ & $1(20)$ & $3(60)$ \\
\hline
\end{tabular}

In the study cohort, there were six women who had undergone hysteroscopic septum resection before their pregnancies. Two of them with history of previous second trimester loss and two with suspected CI according to ease of cervical dilatation during their hysteroscopic septum resection. Except one PTB at the $34^{\text {th }}$ weeks of gestation, all delivered at term after the cerclage procedure.

Remaining two patients had undergone rescue cerclage procedure at 21 and $27^{\text {th }}$ weeks of gestation due to progressive cervical shortening and their pregnancies resulted in delivery at 38 and 35 weeks of gestation, respectively.

All infants in these group were discharged home in well medical condition.

Of the total group, three pregnancies (7.1\%) resulted in late miscarriages (16-19 weeks of gestation) remaining all pregnancies $(92.9 \%)$ ended with a live birth. All deliveries were performed by cesarean section. Overall, the median gestational age at delivery was 37.7 weeks (interquartile range $=1.57$ ) and the median birthweight of the infants was $2970 \mathrm{~g}$ (interquartile range=670). Of those live births, one pregnancy $(1 / 39,2.6 \%)$ resulted in delivery at 26 weeks of gestation and subsequent neonatal death occurred. Two pregnancies $(2 / 39,5.1 \%)$ resulted in live birth between $32-$ 34 weeks of gestation and admission of newborns to the neonatal unit was required, infants were discharged following two to three weeks without sequelae. Seven pregnancies $(7 / 39,17.9 \%)$ resulted with late PTB (between 34 and 37 weeks) while four of the infants needed to be transported to the neonatal unit and discharged following 3 days to 2 weeks. Among the total live births; $29 / 39$ (\%74.4) ended with a term delivery of healthy infants (Table 3 ).

Table 3. Pregnancy and neonatal outcomes of the group Late pregnancy loss

$3(7.1)$

\begin{tabular}{|l|l|}
\hline $\begin{array}{l}\text { Live births } \\
\text { Preterm birth <28weeks }\end{array}$ & $39(92.9)$ \\
\hline Preterm birth between 32-34 weeks & $1(2.6)$ \\
\hline Preterm birth between 34-37 weeks & $2(5.1)$ \\
\hline Term births & $7(17.9)$ \\
\hline Gestational age at delivery (weeks)* & $29(74.4)$ \\
\hline $\begin{array}{l}\text { Interval from the cerclage to delivery } \\
\text { (days)* }\end{array}$ & $37.7(1.5)$ \\
\hline Birthweights of infants $(\mathrm{g})^{*}$ & $161(43)$ \\
\hline
\end{tabular}

Data are presented as $n(\%), *_{\text {median (interquartile range) }}$
In the total group, except one neonatal death due to extremely preterm birth, all infants were discharged from hospital with well condition.

\section{Discussion}

In this single center study, the aim was to evaluate the effectiveness of cervical cerclage placement in women with singleton pregnancies and at risk for preterm birth (PTB) following assisted reproductive treatments. For this purpose, we retrospectively analyzed 42 women with singleton pregnancies following ART who underwent cerclage between 2009-2021. In this cohort of pregnancies, 92.9\% (39/42) ended with a live birth with median gestational age at delivery of 37.7 (IQR:1.57) weeks. Of those live births, $92.3 \%(36 / 39)$ delivered at $>34$ weeks and \%74.4 (29/39) delivered at term.

Except for one neonatal death due to extremely preterm birth at 26 weeks of gestation, remaining all infants are alive and heathy.

We thought that cerclage may potentially reduce early preterm birth risk in IVF pregnancies which at high risk for preterm birth especially if there are findings that may indicate the risk of cervical insufficiency.

The percentage of live births resulting from ART has been increasing worldwide. According to the latest report from ESHRE, attention was drawn to the birth of over 1.8 million babies as a result of nearly 10 million treatment cycles in between 1997 and 2016 in Europe [18]. Moreover, an increasing incidence for children born after ART, as high as 5.1 to $7.7 \%$ were reported in some European countries [18].

Considering the increasing number of pregnancies after ART treatments, the follow-up of these pregnancies also needs a particular attention. In the surveillance report of ART from the USA, the proportion of ART infants to all infants were reported as $1.9 \%$ including more than 75.000 ART infants born in 2017. In addition, a higher percentage of preterm birth was ( 27.8 vs. $9.9 \%$ ) reported among infants conceived after ART than the total birth population which contributed to $5.3 \%$ of all preterm births [19].

The prediction PTB and early interventions for reducing the risk is utmost important for this special population. Apart from the established indications for cerclage placement to reduce the risk of PTB, the effectiveness of the procedure in other risk factors for cervical insufficiency still debatable. Although cervical insufficiency is used as a common term in the clinic, there still is no objective diagnostic test. The cervical passage of $6-8 \mathrm{~mm}$ Hegar dilators without resistance in the pre-pregnancy period has been previously 
used for the diagnosis of cervical insufficiency [20-21]. In this study, we included women who underwent cerclage due to suspicion of cervical insufficiency as determined by $>6$ Hegar dilator passage without resistance during previous hysteroscopic intervention. Among this group, 90.9\% (20/22) had a live birth while $9.1 \%(2 / 22)$ had a late pregnancy loss. The term delivery rate for this group was $68.2 \%(15 / 22)$. In the case series of $\mathrm{Li}$ et al., 10 patients with intrauterine adhesions and a history of typical painless cervical dilation in the second trimester were examined and found that the No. 7 Hegar dilator could pass through the internal cervical os without resistance for all patients either before or after hysteroscopic adhesiolysis.

All patients in their study had undergone pre-pregnancy laparoscopic cervical cerclage. After follow-up for 3 months to 2 years the reported pregnancy rate was $60 \%$ with the live birth rate of $100 \%$ [22].

Presence of congenital uterine anomalies is known to be as another risk factor for PTB [23-26]. The most commonly seen anomaly in the infertile population is canalization defects (septate/ subseptate uterus) [27] which is recommended to be corrected by hysteroscopic resection especially in women with fertility problems $[25,28]$. Although the effectiveness of the procedure on the reproductive outcomes still under debate [23, 29]. Increased miscarriage rates have been documented in women with major congenital anomalies who conceived after ART treatments [30].

In a large prospective study investigating the reproductive outcomes of women with congenital uterine anomalies who underwent ART, including more than 2000 women from the same center, the clinical pregnancy and live birth rates were found to be similar between women with congenital uterine anomalies and controls. However, increased rates of preterm births ( $22 \%$ vs. $14 \%, p=0.03)$ were reported in the women with congenital anomalies compared to the control group [24]. In a meta-analysis including 25 studies, the presence of congenital uterine anomalies were associated with decreased pregnancy rates and poor obstetric outcomes, such as increased abortion rates (RR:1.68, 95\% CI:1.312.15), preterm delivery (<37 weeks, RR:2.21 95\% CI: $1.59-$ 3.08), fetal malpresentation (RR: $4.75,95 \%$ CI: 3.29-6.84) and perinatal mortality (RR:2.43, 95\% CI:1.34-4.42) [26]. Based on this meta-analysis, the authors highlighted that hysteroscopic resection of uterine septum might decrease the spontaneous abortion rates, however the procedure was not associated with significantly increased term deliveries [26]. The majority of the included studies in this meta-analysis were in retrospective nature and the need for further randomized controlled studies were noticed.

Careful follow-up during pregnancy has been recommended for the risk of PTB, even after septum resection [23]. Prophylactic cerclage placement as a preventive measure in women with uterine anomalies without other risk factors has not been evaluated sufficiently so far [25]. In addition, the lack of robust data on preventive measures in women with congenital uterine anomalies is emphasized [23]. In our study population, $14.3 \%(n=6)$ of the patients underwent $H / S$ septum resection before their ART treatments. In this group of patients, all (6/6) delivered after completing 34th weeks of gestation. Among them, 66.6\% (4/6) were term deliveries. Since the increased risk for preterm deliveries is possibly associated with cervical insufficiency in these patients, the pregnancies following surgery and ART treatments may be candidates for the use of prophylactic cerclage procedure.

In the present study, considering all cases, our results showed a term delivery rate of $29 / 39$ (74.4\%) among the live births with the median gestational age at the delivery of 37.7 weeks. Women who gave birth after 34 weeks were $36 / 42$ $(85.7 \%)$ and after 32 weeks were $38 / 42(90.5 \%)$ in this special population. Except one neonatal death due to extremely preterm birth at 26th weeks of gestation, all infants were discharged from the hospital in well condition. These results suggested that the cerclage placement might have beneficial effects in these high risk group of women. ART pregnancies are evaluated as a special group having a higher PTB risk at baseline. Therefore, additional risk factors for PTB should be evaluated in detail with their medical and obstetric history and with the findings of physical examinations. In conclusion, cerclage may be considered in broader indications for ART pregnancies which already have a higher risk for PTB. Other than established indications for the placement of cervical cerclage, there is need for further studies on the effectiveness of the procedure in subgroups of ART pregnancies with suspected cervical insufficiency according to different criteria used.

\section{Disclosure}

Authors have no potential conflicts of interest to disclose.

\section{References}

[1] WHO: recommended definitions, terminology and format for statistical tables related to the perinatal period and use of a new certificate for cause of perinatal deaths. Modifications recommended by FIGO as amended October 14, 1976. Acta Obstet Gynecol Scand. 1977;56(3):247-53. [2] Saigal S, Doyle LW. An overview of mortality and sequelae of preterm birth from infancy to adulthood. Lancet. 2008;371(9608):261-269. doi:10.1016/S0140$6736(08) 60136-1$

[3] Society for Maternal-Fetal Medicine (SMFM). Electronic address: pubs@smfm.org, McIntosh J, Feltovich $\mathrm{H}$, Berghella $V$, Manuck T. The role of routine cervical length screening in selected high- and low-risk women for preterm birth prevention. Am J Obstet Gynecol. 2016;215(3):B2B7. doi:10.1016/j.ajog.2016.04.027

[4] Vogel JP, Chawanpaiboon S, Moller AB, Watananirun K, Bonet $M$, Lumbiganon P. The global epidemiology of preterm birth. Best Pract Res Clin Obstet Gynaecol. 2018;52:3-12. doi:10.1016/j.bpobgyn.2018.04.003 [5] Cavoretto P, Candiani M, Giorgione V, Inversetti A, AbuSaba MM, Tiberio F, et al. Risk of spontaneous preterm birth in singleton pregnancies conceived after IVF/ICSI treatment: meta-analysis of cohort studies. Ultrasound Obstet Gynecol. 2018 Jan;51(1):43-53. doi:

10.1002/uog.18930. PMID: 29114987.

[6] McDonald SD, Han Z, Mulla S, Murphy KE, Beyene J, Ohlsson A; Knowledge Synthesis Group. Preterm birth and low birth weight among in vitro fertilization singletons: a systematic review and meta-analyses. Eur J Obstet Gynecol Reprod Biol. 2009;146(2):138-148.

doi:10.1016/j.ejogrb.2009.05.035

[7] Saccone G, Zullo F, Roman A, Ward A, Maruotti G, Martinelli $P$, et al. Risk of spontaneous preterm birth in IVFconceived twin pregnancies. J Matern Fetal Neonatal Med. 2019 Feb;32(3):369-376. doi: 10.1080/14767058.2017.1378339. Epub 2017 Sep 21. PMID: 28889776.

[8] Sullivan-Pyke CS, Senapati S, Mainigi MA, Barnhart KT. In Vitro fertilization and adverse obstetric and perinatal outcomes. Semin Perinatol. 2017 Oct;41(6):345-353. doi: 10.1053/j.semperi.2017.07.001. Epub 2017 Aug 14. PMID: 28818301; PMCID: PMC5951714.

[9] Pandey S, Shetty A, Hamilton M, Bhattacharya S, Maheshwari A. Obstetric and perinatal outcomes in singleton pregnancies resulting from IVF/ICSI: a systematic review and meta-analysis. Hum Reprod Update. 2012 SepOct;18(5):485-503. doi: 10.1093/humupd/dms018. Epub 2012 May 19. PMID: 22611174.

[10] Sperling JD, Dahlke JD, Gonzalez JM. Cerclage Use: A Review of 3 National Guidelines. Obstet Gynecol Surv. 2017 Apr;72(4):235-241. doi:

10.1097/OGX.0000000000000422. PMID: 28426125. 
[11] Brown R, Gagnon R, Delisle MF. No. 373-Cervical Insufficiency and Cervical Cerclage. J Obstet Gynaecol Can. 2019;41(2):233-247. doi:10.1016/j.jogc.2018.08.009 [12] ACOG Practice Bulletin No.142: Cerclage for the management of cervical insufficiency. Obstet Gynecol. 2014;123(2 Pt 1):372-379.

doi:10.1097/01.AOG.0000443276.68274.cc

[13] Shennan A, To M. Green-top guideline No 60: cervical cerclage. London: Royal College of Obstetricians and Gynaecologists (RCOG); 2011

[14] Berghella V, Rafael TJ, Szychowski JM, Rust OA, Owen J. Cerclage for short cervix on ultrasonography in women with singleton gestations and previous preterm birth: a meta-analysis. Obstet Gynecol. 2011 Mar;117(3):663-671. doi: 10.1097/AOG.0b013e31820ca847. PMID: 21446209.

[15] Alfirevic Z, Stampalija T, Medley N. Cervical stitch (cerclage) for preventing preterm birth in singleton pregnancy. Cochrane Database Syst Rev. 2017 Jun 6;6(6):CD008991. doi: 10.1002/14651858.CD008991.pub3. PMID: 28586127; PMCID: PMC6481522.

[16] Berghella: Berghella V, Odibo AO, To MS, Rust OA, Althuisius SM. Cerclage for short cervix on ultrasonography: meta-analysis of trials using individual patient-level data. Obstet Gynecol. 2005 Jul;106(1):181-9. doi:

10.1097/01.AOG.0000168435.17200.53. PMID: 15994635. [17] Rafael TJ, Berghella V, Alfirevic Z. Cervical stitch (cerclage) for preventing preterm birth in multiple pregnancy. Cochrane Database Syst Rev. 2014 Sep 10;(9):CD009166. doi: 10.1002/14651858.CD009166.pub2. PMID: 25208049.

[18] European IVF-monitoring Consortium (EIM) $\neq$ for the European Society of Human Reproduction and Embryology (ESHRE), Wyns C, Bergh C, Calhaz-Jorge C, De Geyter C, Kupka MS, Motrenko T, et al. ART in Europe, 2016: results generated from European registries by ESHRE. Hum Reprod Open. 2020 Jul 31;2020(3): hoaa032. doi:

10.1093/hropen/hoaa032. PMID: 32760812; PMCID: PMC7394132.

[19] Sunderam S, Kissin DM, Zhang Y, Jewett A, Boulet SL, Warner L, et al. Assisted Reproductive Technology Surveillance - United States, 2017. MMWR Surveill Summ. 2020 Dec 18;69(9):1-20. doi: 10.15585/mmwr.ss6909a1. PMID: 33332294; PMCID: PMC7755269.

[20] Toaff R, Toaff ME, Ballas S, Ophir A. Cervical incompetence: diagnostic and therapeutic aspects. Isr J Med Sci. 1977 Jan;13(1):39-49. PMID: 838569.

[21] Kiwi R, Neuman MR, Merkatz IR, Selim MA, Lysikiewicz A. Determination of the elastic properties of the cervix. Obstet Gynecol. 1988 Apr;71(4):568-74. PMID: 3353048

[22] Li W, Li Y, Zhao X, Cheng C, Burjoo A, Yang Y, et al. Diagnosis and treatment of cervical incompetence combined with intrauterine adhesions. Ann Transl Med. 2020 Feb;8(4):54. doi: 10.21037/atm.2019.12.148. PMID: 32175348; PMCID: PMC7049037.

[23] Akhtar MA, Saravelos SH, Li TC, Jayaprakasan K; Royal College of Obstetricians and Gynaecologists. Reproductive Implications and Management of Congenital Uterine Anomalies: Scientific Impact Paper No. 62 November 2019. BJOG. 2020 Apr;127(5):e1-e13. doi: 10.1111/14710528.15968. Epub 2019 Nov 20. PMID: 31749334.

[24] Prior M, Richardson A, Asif S, Polanski L, Parris-Larkin $M$, Chandler J, et al. Outcome of assisted reproduction in women with congenital uterine anomalies: a prospective observational study. Ultrasound Obstet Gynecol. 2018 Jan;51(1):110-117. doi: 10.1002/uog.18935. PMID: 29055072.

[25] Vaz SA, Dotters-Katz SK, Kuller JA. Diagnosis and Management of Congenital Uterine Anomalies in Pregnancy. Obstet Gynecol Surv. 2017 Mar;72(3):194-201. doi: 10.1097/OGX.0000000000000408. PMID: 28304417. [26] Venetis CA, Papadopoulos SP, Campo R, Gordts S, Tarlatzis BC, Grimbizis GF. Clinical implications of congenital uterine anomalies: a meta-analysis of comparative studies. Reprod Biomed Online. 2014 Dec;29(6):665-83. doi: 10.1016/j.rbmo.2014.09.006. Epub 2014 Sep 21. PMID:
25444500.

[27] Chan YY, Jayaprakasan K, Zamora J, Thornton JG, Raine-Fenning N, Coomarasamy A. The prevalence of congenital uterine anomalies in unselected and high-risk populations: a systematic review. Hum Reprod Update. 2011 Nov-Dec;17(6):761-71. doi:

10.1093/humupd/dmr028. Epub 2011 Jun 24. PMID: 21705770 ; PMCID: PMC3191936.

[28] Theodoridis TD, Pappas PD, Grimbizis GF. Surgical management of congenital uterine anomalies (including indications and surgical techniques). Best Pract Res Clin Obstet Gynaecol. 2019 Aug;59:66-76. doi:

10.1016/j.bpobgyn.2019.02.006. Epub 2019 Feb 15. PMID: 30910446.

[29] Rikken JFW, Kowalik CR, Emanuel MH, Bongers MY, Spinder T, Jansen FW, et al. Septum resection versus expectant management in women with a septate uterus: an international multicentre open-label randomized controlled trial. Hum Reprod. 2021 Apr 20;36(5):1260-1267. doi: 10.1093/humrep/deab037. PMID: 33793794; PMCID: PMC8058590.

[30] Jayaprakasan K, Chan YY, Sur S, Deb S, Clewes JS, Raine-Fenning NJ. Prevalence of uterine anomalies and their impact on early pregnancy in women conceiving after assisted reproduction treatment. Ultrasound Obstet Gynecol. 2011 Jun;37(6):727-32. doi: 10.1002/uog.8968. Epub 2011 Mar 30. PMID: 21337662. 